Full Length Article

\title{
Differences in Selenium Uptake, Distribution and Expression of Selenium Metabolism Genes in Tomatoes
}

\author{
Wanyi Zhao ${ }^{1}$, Weihong $\mathrm{Xu}^{{ }^{*}}$, Yourong Chai ${ }^{2 *}$, Xinbin Zhou ${ }^{1}$, Mingzhong Zhang ${ }^{1}$ and Wenwen Xie ${ }^{1}$ \\ ${ }^{1}$ College of Resources and Environmental Sciences, Southwest University, Chongqing 400715, People's Republic of China \\ ${ }^{2}$ College of Agronomy and Biotechnology, Southwest University, Chongqing 400715, People' s Republic of China \\ *For correspondence: xuwei_hong@163.com; chaiyourong1@163.com
}

\begin{abstract}
Effects of different levels of selenium $\left(0,5\right.$ and $\left.10 \mathrm{mg} \cdot \mathrm{kg}^{-1}\right)$ on selenium uptake, distribution, and the expression levels of Se metabolism genes were compared with three tomato (Solanum lycopersicum L.) varieties (KT30, Defumm-8 and Luobeiqi). The results showed that Se inhibited the expression levels of APS reductase in varieties of KT30 and Luobeiqi; however, there was no significant difference in variety Defumm-8. Selenium also promoted expression levels of ATP sulfurylase of the tomato varieties. The expression levels of cysteine desulfurase of variety KT30 and variety Defumm- 8 first decreased and then increased with the increasing Se concentration; however, expression levels of Se were lower than the control, and expression levels of Se in leaves of variety Luobeiqi increased. The Se concentration markedly decreased the expression levels of Sadenosyl-1-Met:1-Met S-methyltransferase in the three varieties, except variety Defumm- 8 with Se at $5 \mathrm{mg} \cdot \mathrm{kg}^{-1}$. Furthermore, the Se concentration markedly decreased expression levels of serine acetyltransferase of variety KT30 and variety Defumm-8, but expression levels of leaves of variety Luobeiqi increased. Expression levels of serine acetyltransferase in variety Luobeiqi increased with the increasing Se concentration but decreased in KT30 and Defumm-8. Expression levels of SeCys methyltransferase (SMT) in Luobeiqi and KT30 were reduced by Se, while promoted in Defumm-8. The Se treatment promoted expression levels of APS in three tomato varieties. C 2017 Friends Science Publishers
\end{abstract}

Keywords: Tomato varieties; Selenium uptake; Distribution; Selenium metabolism genes

\section{Introduction}

Selenium (Se), a vital trace element for humans, is important for preventing disease, improving health, and preventing aging and has been considered a life-protecting agent. Selenium deficiency can cause a series of symptoms, such as cardiovascular disease, Kaschin-Beck disease and Keshan disease. The Se content of the soil is typically low, and there are more than 40 countries and regions worldwide where people experience Se deficiency. In China, about 72\% county (city) are Se deficiency areas, of which nearly $1 / 3$ are severe Se deficiency areas. Improved living standards have resulted in more attention being given to health, and people have begun taking Se supplements. Selenium supplements can be manufactured from inorganic chemicals, such as sodium selenite, but the absorption rate in the human body is low, with the risk of side effects (Wen, 2006). Researches have shown that consumption of plant products containing a high Se content, is the most efficient and safe way of Se supplementation (Finley and Davis, 2001; Chen et al., 2008).

The contents of selenium in plants varied greatly, because of plant species, planting environment, and the way of cultivation, etc. There is a great difference in the content of selenium in species, and there is a significant difference in the contents of selenium in different genotypes (Zhang et al, 2006). Glutathione peroxidase (GSH-Px) was the first enzyme reported in the literature as a selenium containing enzyme, which has been found out to have four categories kinds of GSH-Px family members (Miao et al., 2005). GSH-Px may be one of family member of the plant, which may or may be different vary in different developmental stages and in different stress conditions. The mRNA levels of GSH-Px increased steadily under different environmental stresses e.g., pathogen infection, high salt and heavy metals, etc. (Avsian-Kretchmer and Lev-Yadun, 2004) Therefore, GSH-Px may play a vital part in the process of oxidative signal transduction in plants (Freeman et al., 2006, 2010).

In recent studies, APS play modulates the reduction of selenite and Se assimilation because of a strong similarity between sulfur and Se; it has also been illustrated that the limit of $\mathrm{Se}$ assimilation is selenate reduction $(\mathrm{Du}$ et al., 2007). Overexpressed APS in transgenic plants promote the rate of this process and increases accumulation and tolerance of Se (Sors et al., 2005). Many studies have proven that cysteine desulfurase $(C y s D)$, S-adenosyl-1Met:l-Met S-methyltransferase (MMT) (Berken et al., 2002), serine acetyltransferase (SAT) (Van Hoewyk et al., 2008), and SeCys methyltransferase (SMT) were also the

To cite this paper: Zhao, W., W. Xu, Y. Chai, X. Zhou, M. Zhang and W. Xie, 2017. Differences in selenium uptake, distribution and expression of selenium metabolism genes in tomatoes. Int. J. Agric. Biol., 19: 528-534 
main genes for plant metabolism and Se accumulation (Berken et al., 2002). Apart from possessing Cys desulfurase activity, NifS-like proteins can also be characterized as SeCys lyases able to cleave selenocysteine to form alanine and elemental selenium (Mihara et al., 1997). The synthesis of Se-Met is involved in possibly by homo-Cys S-methyltransferase or Met synthase. Regarding to the sulfur assimilation, Terry et al. (2000) reported that Se-Met is methylated to Se-methyl Se-Met (SeMM) by the Sadenosyl-1-Met:Met-S- methyltransferase.

Selenocysteine methyltransferase (SMT), a central enzyme in Se hyperaccumulators, which can methylate SeCys and inhibit toxicity by preventing SeCys from being misincorporated into proteins (Neuhierl and Böck, 1996). Therefore, selenate can be converted into methylselenocysteine and g-glutamylmethylselenocysteine rapidly by the hyperaccumulator Astragalus bisulcatus (Dunnill and Fowden, 1967; Zhang et al., 2006). The gene encoding SMT not only has been cloned from $A$. bisulcatus (Neuhierl and Böck, 1996) but overexpressed in Arabidopsis thaliana and Brassica juncea; The strengthen Se tolerance and accumulation were brought about by this when plants were given selenite $\left(\mathrm{SeO}_{3}{ }^{2-}\right)$ instead of selenate (Sors et al., 2005). In hyperaccumulators, accumulation of total Se was evidently higher than that was discovered in the SMT transgenic plants, which indicates that SMT enzyme is seemly related that have a synergistic interactions of Se hyperaccumulators. Ellis et al. (2004) reported that it cannot be proved that the capacity differences in enzyme are related to reduction or assimilattion $\mathrm{S}$, which is significant for $\mathrm{Se}$ hyperaccumulated $A$. bisulcatus.

Sors et al. (2005) also proposed transgenic A. thaliana overexpressing APR (APS reductase) and ATP sulfurylase played significant roles in a greater selenate reduction of total Se, however the overexpressing in SAT (serine acetyl transferase) led to a tiny reduction in organic selenium. Generally, total Se accumulation in shoots was relatively low in the transgenic plants overexpressing ATPS, SAT and PaAPR ( $P$. aeruginosa APR). The plant root growth was affected by selenate treatment within ATPS and SAT overexpressors, besides, less in the PaAPR transgenic plants. Thereby, it draws a conclusion that ATPS and APR enzymes are vital correlated with selenate reduction in plants (Sors et al., 2005). In this research, the effect of various Se concentrations on growth and on the Se uptake and accumulation in three tomato varieties were determined. To explore differences in Se accumulations in these tomato varieties, the genes connected with Se metabolism and absorption in tomato and the expression levels during growth were also examined.

\section{Materials and Methods}

\section{Plant Material, Soil and Se Treatments}

Soil was collected from the Jiulongpo district in Chongqing municipality, China. The soil $\mathrm{pH}$ was 6.03 , organic matter content was $37.35 \mathrm{~g} \cdot \mathrm{kg}^{-1}$, total nitrogen (TN) content was $2.62 \mathrm{~g} \cdot \mathrm{kg}^{-1}$, available nitrogen content in soil was 105 $\mathrm{mg} \cdot \mathrm{kg}^{-1}$, available phosphorous content $13.1 \mathrm{mg} \cdot \mathrm{kg}^{-1}$, available potassium content was $100.9 \mathrm{mg} \cdot \mathrm{kg}^{-1}$, cation exchange capacity (CEC) was $0.192 \mathrm{~mol} \cdot \mathrm{kg}^{-1}$, total Se content was $0.26 \mathrm{mg} \cdot \mathrm{kg}^{-1}$, and available Se was 0.017 $\mathrm{mg} \cdot \mathrm{kg}^{-1}$. Seedlings of three tomato varieties (KT30, Defumm-8 and Luobeiqi) were purchased from Chongqing Academy of Agricultural Sciences.

Three levels s of Se $\left(0,5\right.$ and $\left.10 \mathrm{mg} \cdot \mathrm{kg}^{-1}\right)$ prepared from $\mathrm{Na}_{2} \mathrm{SeO}_{3}$ were set up for the pot experiment. Moreover, air-dried soil (5 kg) was sieved using a 40-mesh sieve, and homogeneously mixed with the $\mathrm{Na}_{2} \mathrm{SeO}_{3}$ solution, put in a plastic pot (diameter, $25 \mathrm{~cm}$; height, $17 \mathrm{~cm}$ ), all treatments were performed in triplicate and arranged at random. The tomato seedlings were transplanted at three or four leaf stage on March 2, 2013. Nitrogen was applied basically in 180 $\mathrm{mg} \cdot \mathrm{L}^{-1}$ and in three installments: $40 \%$ for basal and $30 \%$ each for seedling and flowering stages, $\mathrm{P}$ fertilizer $\left(\mathrm{NH}_{4} \mathrm{H}_{2} \mathrm{PO}_{4}\right)$ and $\mathrm{K}(\mathrm{KCl})$ were applied in 100 and 150 $\mathrm{mg} \cdot \mathrm{L}^{-1}$ respectively in the basic fertilizer, productivity was recorded since the first tomato fruit was born. The process of the greenhouse experiment was took three months, and the production was recorded (Xie et al., 2014).

\section{Analysis of Soil Physicochemical Properties}

The soil $\mathrm{pH}$ was measured in 1:5 (soil:water). Extractable $\mathrm{P}$ and cation exchange capacity (CEC) were measured according to Rayment and Higginson (1992), while the soil organic matter was determined with the method of McCleod (1975). The concentration of extractable Se was determined via $\mathrm{KH}_{2} \mathrm{PO}_{4}\left(0.016 \mathrm{~mol} \cdot \mathrm{L}^{-1}\right)$ extraction $[10 \mathrm{~g}$ soil (dry weight) to $30 \mathrm{~mL}$ of $\mathrm{KH}_{2} \mathrm{PO}_{4}(\mathrm{w} / \mathrm{v})$ ] followed by atomic fluorescence spectrometry analysis (Zhang et al., 2014).

\section{Analysis of Se Concentrations in the Plants}

Dried plant samples were ground and digested at $170^{\circ} \mathrm{C}$ using $10 \mathrm{~mL}(8 \mathrm{~mL}$ of ultrapure nitric acid and $2 \mathrm{~mL}$ of perchloric acid) of acid mixture (Kyodan et al., 1988). The acid mixture was heated until white smoke appeared; further, $10 \mathrm{~mL}$ of $6 \mathrm{~mol} \cdot \mathrm{L}^{-1}$ hydrochloric acid was added, and the mixture was heated until the white smoke reappeared. The residual sample was then diluted in $25 \mathrm{~mL}$ of ultrapure water. The concentration of Se in the solution was analyzed using hydride generation atomic fluorescence spectrometry (PF6.3, Beijing Purkinje General Instrument Co. Ltd., China).

\section{Detection of Gene Expression}

Total RNA extraction: Total RNA was extracted from the plant material with RNA extraction kit purchased from Huashun Biotechnology Company. RLP lysate: RLA and Plant-PLUS were mixed at $4: 1(\mathrm{~V} / \mathrm{V})$, adding $2 \%$ of the 
total volume of 2-ME. Fresh samples $(100 \mathrm{mg})$ kept at $-80^{\circ} \mathrm{C}$ were powdered under liquid nitrogen. The samples were added to $1.5 \mathrm{~mL}$ centrifuge tubes pre-filled with 600 $\mu \mathrm{L}$ RLP lysates and vibrated for 2 min for mixing the samples before the liquid nitrogen completely evaporated. Let sit for five minutes, then subjected to reverse oscillation for $30 \mathrm{~s}$ after adding $200 \mu \mathrm{L}$ chloroform, followed by $3 \mathrm{~min}$ at room temperature. Centrifuged for $5 \mathrm{~min}$ at $12000 \mathrm{rpm}$, the supernatant was transferred to another $1.5 \mathrm{~mL}$ centrifuge tube of and mixed with $250 \mu \mathrm{L} 75 \%$ ethanol after through mixing and then put them to the RNA adsorption column. Then centrifuged for $1 \mathrm{~min}$ at $12000 \mathrm{rpm}$, the liquid was discarded in the collection tube, and the adsorption column was put back in the original collection tube. Then $500 \mu \mathrm{L}$ RP (protein-free solution) was added, placed for $1 \mathrm{~min}$ and centrifuged for $30 \mathrm{~s}$ at $12000 \mathrm{rpm}$. Next, the liquid was discarded in the collection tube and the adsorption column was put back in the original collection tube. $500 \mu \mathrm{L}$ liquid of W3 (75\% ethanol) was added, placed for $1 \mathrm{~min}$, and centrifuged for $15 \mathrm{~s}$ at $12000 \mathrm{rpm}$; further, the supernatant was discarded in the collection tube, the centrifuge tube was washed with $1 \mathrm{~mL} 75 \%$ ethanol and centrifuged for $1 \mathrm{~min}$ at $12,000 \mathrm{rpm}$. After that the adsorption column was put into another clean $1.5 \mathrm{~mL}$ centrifuge tube. Finally, $50 \mu \mathrm{L}$ of DEPC water was added to the center of the membrane adsorption and air dried for $2 \mathrm{~min}$, then centrifuged for 1 $\mathrm{min}$ at $13000 \mathrm{rpm}$. Lastly, the eluent contained total RNA in the samples. Two tubes were taken for electrophoresis and spectrophotometer detection after packing, and the rest were quickly preserved in refrigerator at $-80^{\circ} \mathrm{C}$.

Purification of total RNA: RNase-free DNase I (Code No. D2215) (TARALA) was used for removing trace amounts of DNA in the RNA sampl. 20-50 $\mu \mathrm{g}$ total RNA, $5 \mu \mathrm{L}$ in $10 \times$ DNase I buffer, $2 \mu \mathrm{L}$ DNase I (RNase-free, $5 \mathrm{U} / \mu \mathrm{L}$ ), and $0.5 \mu \mathrm{L}$ RNase inhibitor $(40 \mathrm{U} / \mu \mathrm{L})$ were added in microcentrifugal tubes, and then added DEPC-treated water to a total volume of $50 \mu \mathrm{L}$. The solutions were reacted for $30 \mathrm{~min}$ at $37^{\circ} \mathrm{C}$. $50 \mu \mathrm{L}$ DEPC-treated water was added to make a total volume of $100 \mu \mathrm{L}$. The same volume $(100 \mu \mathrm{L})$ of phenol/chloroform/isoamyl alcohol (25:24:1) was added and mixed thoroughly. The solutions were centrifuged for 5 min at $12000 \mathrm{rpm}$, and the upper supernatant was removed into another microcentrifugal tube. The same volume (100 $\mu \mathrm{L})$ of chloroform/isoamyl alcohol $(v: v=24: 1)$ was added and mixed thoroughly. The solutions were allowed to stand at room temperature and centrifuged for $5 \mathrm{~min}$ at 12000 $\mathrm{rpm}$; the upper supernatant was transferred to another microcentrifugal tube. The $1 / 10$ volume $(10 \mu \mathrm{L})$ of $3 \mathrm{M}$ $\mathrm{NaOAC}(\mathrm{pH} 5.2)$ and $250 \mu \mathrm{L}$ precooling ethanol were added and placed for $30-60 \mathrm{~min}$ at $-20^{\circ} \mathrm{C}$. The solutions were centrifuged for $10 \mathrm{~min}$ at $12000 \mathrm{rpm}$ at $4^{\circ} \mathrm{C}$; the supernatant was abandoned and the precipitate was recovered. The precipitation was washed with $2-4^{\circ} \mathrm{C} 70 \%$ ethanol and centrifuged for $10 \mathrm{~min}$ at $12000 \mathrm{rpm}$ at $4{ }^{\circ} \mathrm{C}$ and the supernatant was then discarded and the precipitate was air or blow dried. The precipitate was then dissolved with a proper amount of RNase-free $\mathrm{H}_{2} \mathrm{O}$, providing purified RNA. RNA detection: RNA $(1 \mu \mathrm{L})$ was taken, and the OD values were set up at $260 \mathrm{~nm}$ and $280 \mathrm{~nm}$ by Nanodrop $2000 \mathrm{UV}$ vis spectrophotometer (Thermo Scientific, USA). Concentration calculation: For single-stranded RNA, the RNA concentration was $40 \mu \mathrm{g} \cdot \mathrm{mL}^{-1}$ when $\mathrm{OD}_{260}=1.0$. The RNA concentration is calculated according to the method. Purity analysis: The ideal $\mathrm{OD}_{260} / 280$ of RNA samples should be 1.7-2.0. Further, $1 \%$ agarose gel and $1 \times \mathrm{TAE}$ electrophoretic buffer were prepared; $5 \mu \mathrm{L}$ of RNA was taken, and $2 \mu \mathrm{L}$ bromophenol blue was added to it. This mixture was then thoroughly mixed, electrophoresed $(90 \mathrm{~V}$, $1-2 \mathrm{~h}$ ), and photos were captured with E-Gel Imager.

\section{Synthesis of Reverse Transcription cDNA}

A $20 \mu \mathrm{L}$ reaction mixture was put in the microcentrifuge tubes, and cooled on ice, added $2 \mu \mathrm{g}$ total RNA and $1 \mu \mathrm{L}$ Olig (dT) 18 solutions, then add to $11 \mu \mathrm{L}$ with DEPC-treated $\mathrm{H}_{2} \mathrm{O}$, mixed softly and gently centrifuged for $5 \mathrm{~s}$. The solutions were kept $70^{\circ} \mathrm{C}$ in a water bath for 5 min, quickly transferred to an ice bath for $5 \mathrm{~min}$, and gently centrifuged for 5 s. $4 \mu \mathrm{L} 5 \times$ Buffer, $1 \mu \mathrm{L}$ RNase Inhibitor $(40 \mathrm{U} / \mu \mathrm{L}), 1$ $\mu \mathrm{L} \operatorname{MMLV}(200 \mathrm{U} / \mu \mathrm{L})$ and $2 \mu \mathrm{L}$ dNTP $(10 \mathrm{mM})$ were added to the tubes. The solutions were gently shaken and centrifuged at a low speed for $5 \mathrm{~s}$. The solutions were kept at $42^{\circ} \mathrm{C}$ water bath for $1 \mathrm{~h}$. The temperature of solutions was maintained in $70^{\circ} \mathrm{C}$ for $15 \mathrm{~min}$, following which, the reaction was terminated, and the solutions stored at $-20^{\circ} \mathrm{C}$.

\section{Primer Design and Synthesis}

Six genes associated with Se metabolism were examined. According to cDNA sequence in NCBI GenBank of tomato (Solanum lycopersicum L) and other solanaceae crops (Kabelka et al., 2002; Barry and Pandey, 2009) designing the RT-PCR gene-specific primers by Oligo 6.0 software (Xiao et al., 2015).

\section{PCR Amplification of cDNA}

Take the acquired cDNA, specific amplified with ABI-9700 instrument, reaction system (total volume is $25 \mu \mathrm{L}$ ) included with $2.5 \mu \mathrm{L} 10 \times$ Buffer (including $\left.\mathrm{Mg}^{2+}\right), 0.5 \mu \mathrm{L}$ dNTP (10 $\mathrm{mM}), 0.5 \mu \mathrm{L}$ forward primer $(10 \mu \mathrm{M}), 0.5 \mu \mathrm{L}$ reverse primer $(10 \mu \mathrm{M}), 0.3 \mu \mathrm{L}$ Taq DNA polymerase $(5 \mathrm{U} / \mu \mathrm{L}), 0.25 \mu \mathrm{L}$ cDNA template, and then add $\mathrm{dd}_{2} \mathrm{O}$ to a total volume of $25 \mu \mathrm{L}$. PCR reaction program included $94^{\circ} \mathrm{C}$ initial denaturation for $2 \mathrm{~min}$, and $94^{\circ} \mathrm{C}$ denaturation for $40 \mathrm{~s}$, and $52^{\circ} \mathrm{C}-60^{\circ} \mathrm{C}$ annealing temperature (depends on the specific reaction, APR $56^{\circ} \mathrm{C}$, APS $60^{\circ} \mathrm{C}$, CysD $60^{\circ} \mathrm{C}$, MMT $60^{\circ} \mathrm{C}$, SAT $52^{\circ} \mathrm{C}$, and SMT $58^{\circ} \mathrm{C}$, etc. ) for $1 \mathrm{~min}$, and $72^{\circ} \mathrm{C}$ for 45 $\mathrm{s}$, and 30 cycles, and then $72^{\circ} \mathrm{C}$ for $10 \mathrm{~min}$. PCR products with detected with electrophoresis $1.2 \%$ agarose gel (including GoldView, GV), and images were taken with ultraviolet transilluminator. 


\section{Real-time Quantitative PCR}

The cDNA obtained by reverse transcription was diluted 25fold with dd $\mathrm{H}_{2} \mathrm{O}$, and its specificity was detected with qRTPCR with the 25S rRNA gene as the standard (Levesque et al., 1990) using SYBR Premix Ex TaqTM II (Perfect Real Time) kit provided by TaKaRa. The PCR amplification reaction system include $10 \mu \mathrm{SSYBR}^{\circledR}$ Premix Ex Taq ${ }^{\mathrm{TM}}$ II $(2 \times), 0.8 \mu \mathrm{L}$ F-primer $(10 \mu \mathrm{mol} / \mathrm{L}), 0.8 \mu \mathrm{L}$ R-primer $(10$ $\mu \mathrm{mol} / \mathrm{L}), 0.4 \mu \mathrm{L}$ ROX Reference Dye II (50×), and $100 \mathrm{ng}$ cDNA template, then added $\mathrm{ddH}_{2} \mathrm{O}$ up to a total volume of $20 \mu \mathrm{L}$. Amplification reaction conditions were $95^{\circ} \mathrm{C}$ predenatured for $30 \mathrm{~s}, 95^{\circ} \mathrm{C}$ denatured for $5 \mathrm{~s}$, corresponding annealing temperature annealing for $30 \mathrm{~s}$, extension of $30 \mathrm{~s}$, 40 cycles, and then $72^{\circ} \mathrm{C}$ extension of $10 \mathrm{~min}$. PCR products were assayed using a rapid automated capillary electrophoresis system. Each sample was repeated three times, while 25S rRNA gene was used as the standard gene.

\section{Statistical Analysis}

Three-way analysis of univariate ANOVA and correlation analysis were performed using SPSS version 21.0 package (SPSS, 2009). The variables analyzed separately were Se concentration and Se uptake in tomato. The transfer factors (TF; proportion of Se concentration in shoot to that in roots) were also analyzed to three-way univariate ANOVA. The level of significance was 0.05 (Xu et al., 2010).

\section{Results}

\section{Concentration of Se in Fruit, Leaf, Stem and Root}

The Se concentrations in fruit, leaf, stem and root were significantly different $(p \leq 0.05)$ between Se treatments and between varieties (Fig. 1). Considering the effects of Se treatments on all varieties, Se contents in plant tissues were in the order root $\left(9.898 \mathrm{mg} \cdot \mathrm{kg}^{-1}\right)>$ leaf $\left(2.299 \mathrm{mg} \cdot \mathrm{kg}^{-1}\right)>$ stem $\left(1.297 \mathrm{mg} \cdot \mathrm{kg}^{-1}\right)>$ fruit $\left(1.176 \mathrm{mg} \cdot \mathrm{kg}^{-1}\right)$. Furthermore, Se concentrations in root, stem, leaf, and fruit increased with an increase in the applied Se fertilizer. The Se concentration in the root of $10 \mathrm{mg} \cdot \mathrm{kg}^{-1} \mathrm{Se}$ treatment was 2.25 times that of the $5 \mathrm{mg} \cdot \mathrm{kg}^{-1} \mathrm{Se}$ treatment for variety KT30. In the stem, leaf and fruit were 3.04, 1.81, and 2.73 times that of the 5 $\mathrm{mg} \cdot \mathrm{kg}^{-1}$ Se treatment. For variety Defumm- 8 , the Se content in the root was 1.64 times that of $5 \mathrm{mg} \cdot \mathrm{kg}^{-1} \mathrm{Se}$, whereas in the stem, leaf, and fruit were 3.28, 1.83 and 2.10 that of $5 \mathrm{mg} \cdot \mathrm{kg}^{-1} \mathrm{Se}$ treatment. For variety Luobeiqi, the Se concentration in the root was 1.61 times that of the 5 $\mathrm{mg} \cdot \mathrm{kg}^{-1} \mathrm{Se}$ treatment, whereas the stem, leaf and fruit were $2.82,2.63$ and 3.04 times that of the $5 \mathrm{mg} \cdot \mathrm{kg}^{-1} \mathrm{Se}$ treatment. Highest fruit Se concentration was $2.778 \mathrm{mg} \cdot \mathrm{kg}^{-1}$ in variety Luobeiqi at the $10 \mathrm{mg} \cdot \mathrm{kg}^{-1} \mathrm{Se}$ treatment.

\section{Se Accumulation in Fruit, Leaf, Stem and Root}

A marked difference was found in the Se content in the leaves, stem, fruit, and roots between the three varieties and between the different Se concentrations (Fig. 2). The Se content in different tissues of tomato increased with the increasing Se concentration in the soil and reached a maximum at $10 \mathrm{mg} \cdot \mathrm{kg}^{-1} \mathrm{Se}$ treatment. The Se accumulation (per pot) in the root was 16.19-30.92 times, for the stem was 17.03-21.69, for the leaves was $12.80-25.01$, and for the fruit was 18.02-25.21 times that of the control. Moreover, the Se accumulation in the different tissues of tomato were different and was in order of stem $\approx$ leaf $>$ root $\approx$ fruit $(p \leq$ $0.05)$. In this experimental condition, after treated with $\mathrm{Se}$, fruit Se accumulation in variety Defumm- 8 was higher than that in variety KT30 and variety Luobeiqi. On the other hand, whether treated with Se or not, total Se concentration in variety KT30 and variety Luobeiqi were higher than that in variety Defumm-8. Highest total Se concentration was $206.10 \mathrm{ug} \cdot$ pot $^{-1}$ in variety KT30 at $10 \mathrm{mg} \cdot \mathrm{kg}^{-1} \mathrm{Se}$ treatment.

\section{Detection of Se Metabolism Gene Expression}

Real-time PCR results of APR and six gene expression levels between the different tomato varieties and concentration are shown in Fig. 3 and Fig. 4. The expression level of APR in variety KT30 was the highest in the treatment without $\mathrm{Se}$, and it markedly decreased with $\mathrm{Se}$, whereas there was no marked difference of APR expression in in different treatments of variety Defumm- 8 . There was marked difference of APR expression in different treatments of variety Luobeiqi, and it was decreased with the increasing Se concentration and reached a minimum at 10 $\mathrm{mg} \cdot \mathrm{kg}^{-1}$. Expression levels of ATP sulfurylase (APS) of variety KT30 first decreased and then increased and reached maximum at $10 \mathrm{mg} \cdot \mathrm{kg}^{-1} \mathrm{Se}$ treatment; it was 3.67 times that of the control. The Se concentration markedly promoted expressions of APS of variety Defumm- 8 and variety Luobeiqi, which increased with the increasing soil Se concentration. Moreover, expression levels of CysD of variety KT30 and variety Defumm- 8 revealed the same trend with the increasing Se concentration: first decreased, then increased, and reached minimum at $5 \mathrm{mg} \cdot \mathrm{kg}^{-1} \mathrm{Se}$ treatment, which decreased by $21.43 \%$ and $30.77 \%$, respectively, compared with the control. However, Se expression levels at $10 \mathrm{mg} \mathrm{kg}^{-1} \mathrm{Se}$ treatments were lower than that of the control. The Se treatment promoted the expression of CysD of variety Luobeiqi, and it reached a maximum at $5 \mathrm{mg} \cdot \mathrm{kg}^{-1} \mathrm{Se}$ treatment. The Se concentration markedly decreased expression levels of MMT of variety Luobeiqi and variety KT30, both increased with the increasing Se concentration; expression of SAT of variety Defumm- 8 reached a maximum at $5 \mathrm{mg} \mathrm{kg}{ }^{-1}$ Se treatment, while reduced at $10 \mathrm{mg} \cdot \mathrm{kg}^{-1}$ Se treatment. Expression levels of SAT of variety KT30 and variety Defumm- 8 revealed the same trend with the increasing Se concentration: first decreased and then increased; however, they were lower than the control. The expression level of SAT of variety Luobeiqi increased with the increasing Se concentration and 


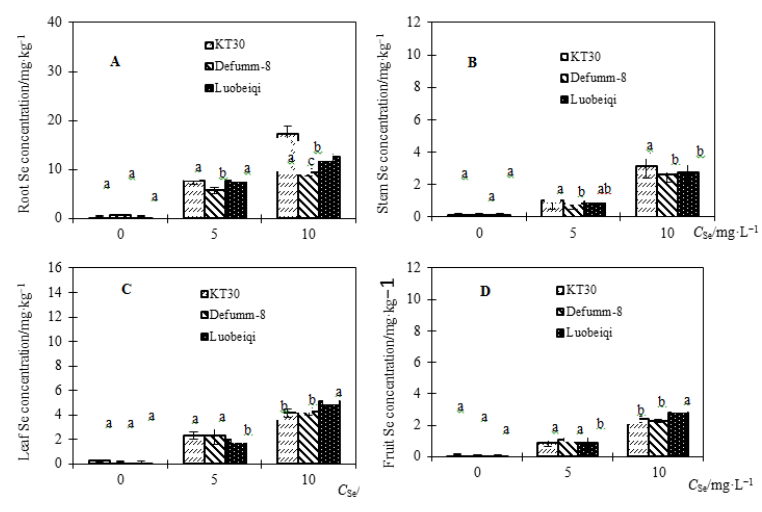

Fig. 1: Impacts of different Se concentrations on the Se content of root (A), stem (B), leaf (C) and fruit (D) in different tomato varieties ${ }^{\psi}$

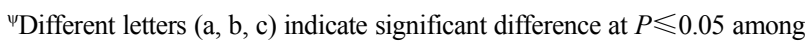
different Se levels
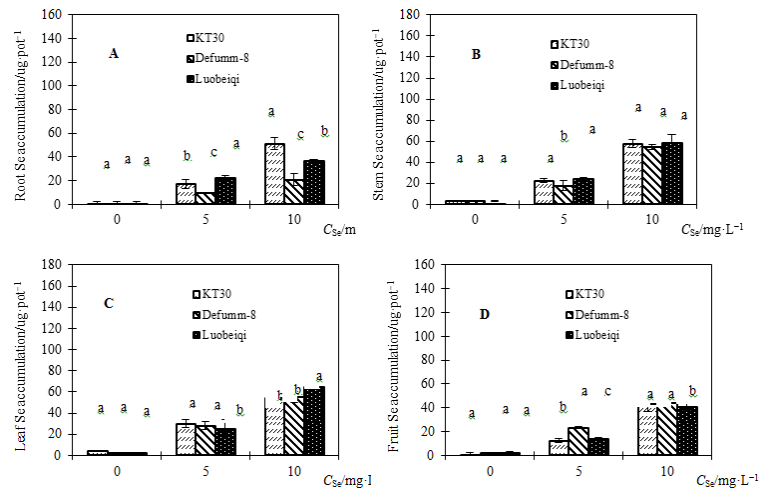

Fig. 2: Variations in Se accumulation in root (A), stem (B), leaf (C) and fruit (D) for the different tomato varieties ${ }^{\psi}$ ${ }^{\psi}$ Different letters $(\mathrm{a}, \mathrm{b}, \mathrm{c})$ indicate significant difference at $P \leqslant 0.05$ among different Se levels

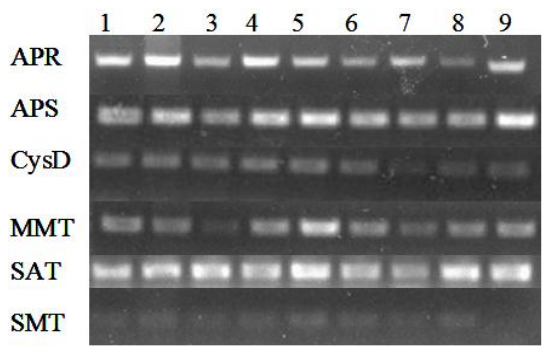

Fig. 3: Real time fluorescent quantitative PCR analysis of Se metabolism associated genes in leaf of different tomato varieties $^{\psi}$

reached a maximum at $10 \mathrm{mg} \cdot \mathrm{kg}^{-1}$ Se treatment. Expression levels of SMT of variety Luobeiqi and variety KT30 were inhibited by Se treatment, whereas it was promoted in variety Defumm-8.

${ }^{\psi}$ Number 1, 2 and 3 indicate varieties KT30, Defumm8 and Luobeiqi at no Se treatment; 4, 5 and 6 indicated varieties KT30, Defumm- 8 and Luobeiqi at $5 \mathrm{mg} \cdot \mathrm{kg}^{-1} \mathrm{Se}$ treatment; 7, 8 and 9 indicated varieties KT30, Defumm-8 and Luobeiqi at $5 \mathrm{mg} \cdot \mathrm{kg}^{-1}$ Se treatment, respectively.

\section{Discussion}

In this experiment, the Se content in roots of tomato was the highest, followed by leaf, stem and then fruit was the lowest, which was similar to the results of many scholars. For example, Shi et al. (1993) studied the absorption, distribution, and transformation of $\mathrm{Se}$ in tomato and found that the Se content in various organs in the plant in the order of root $>$ leaf $>$ stem $>$ fruit $>$ flowers. Tian et al. (2005) had a similar report, with different Se concentrations; the Se content in different parts of ryegrass was in order of roots $>$ leaves $>$ stems (Tian et al., 2005). The selenium transfering from soil to plant depends upon plant species, form of Se supply, soil type, concentration and so forth (Munierlamy et al., 2007). Furthermore, the content of Se in the organs is related with Se chemical form. In soil, selenite adsorbed by carbonate, amorphous iron or aluminum content mainly exsists in exchangeable speciation and carbonate bound form that cannot be uptaken largely by plants ( $\mathrm{Li}$ et al., 2015), whereas Se (VI) has high mobility and validity in soil which indicates that the selenate accumulation and absorption capacity of plants is stronger than selenite. There is a great difference in the plant uptake, transformation and distribution of Se (VI) and Se (IV), and Se (VI) and Se (IV) absorption and transport mechanism are relatively independent. Eustice et al. (1980) found that selenate was more easily transported than selenite and the organic Se selenomethionine (SMT), Terry et al. (2000) demonstrated the same conclusion. When selenate was absorbed, the ratio of plant Se concentration and root Se concentration was $1.4-1.72$, while the ratio range was $0.6-1$ when they absorbed selenomethionine (SMT); the ratio range was $<0.5$ when they absorbed selenite (Zayed et al., 1998). The Se content in cabbage shoots was less than underground treated by Se (IV), while it was reverse for Se (VI) treatment (Fu et al., 2011). There was 50\% selenate absorbed by root of legume was transported to plant in $3 \mathrm{~h}$, whereas for selenite, the majority remained in the roots, and only a small portion was transported to shoots (Arvy, 1993). Selenite was rarely transported to plants because it may quickly be converted to organic Se (such as SMT), which remains in the root (Zayed et al., 1998). Further studies are required on synthesizing selenite in root and the transportation of synthetic substances of selenite to shoots.

The mechanism of selenium accumulation in fruits and grains has important theoretical and practical significance in improving the selenium content in fruits and grains (Zhou et al., 2016). The Se content in tomato stems and leaves was greater than in roots, indicating that more root Se transported to stems and leaves, and was enriched in fruits. Zhou et al. (2007) found that when Se was present in abundance, it was easily transported to shoots and was 

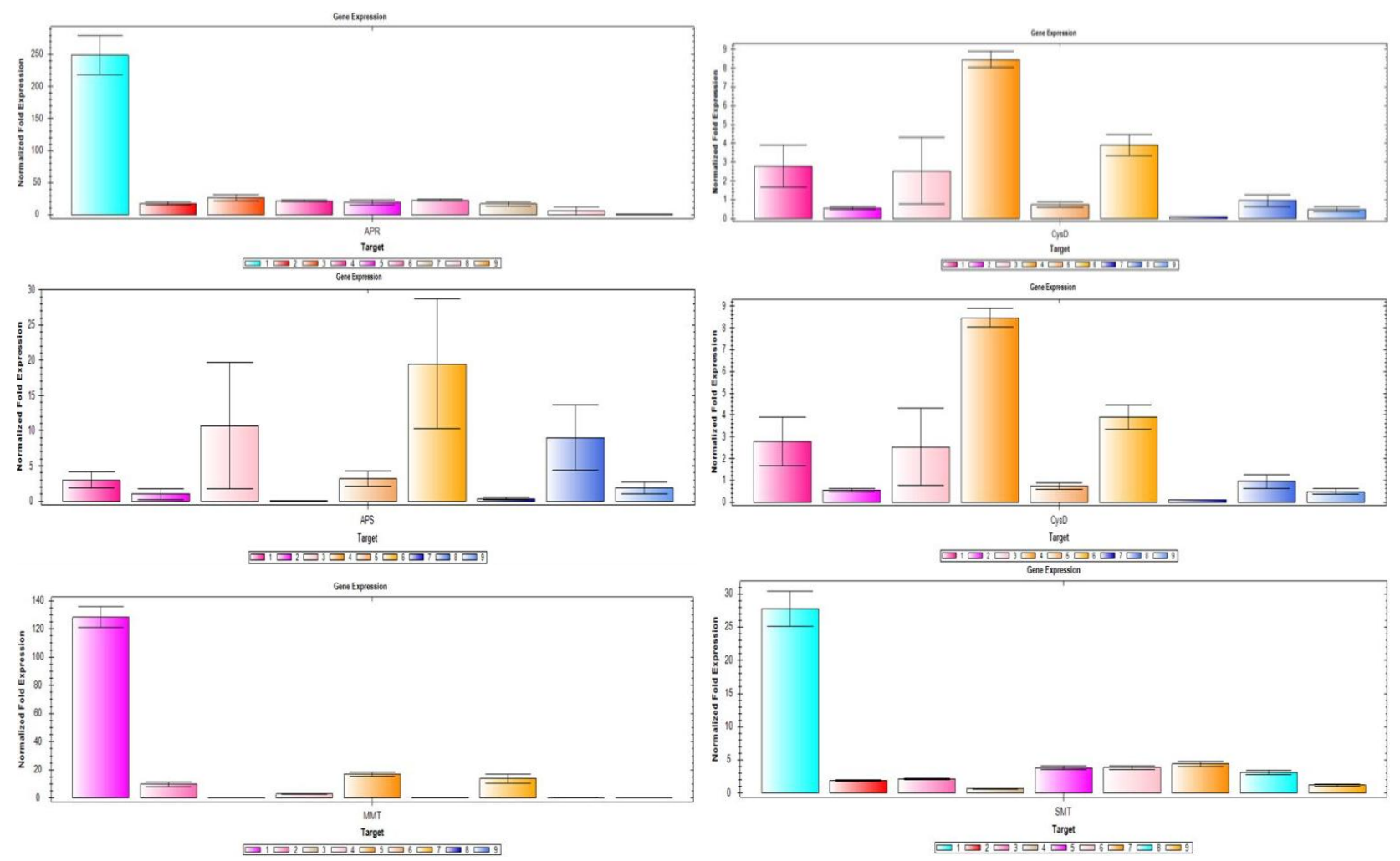

Fig. 4: Real-time PCR analysis of Se metabolism associated genes in tomato leaf $\psi$

"Number 1,2 and 3 indicated varieties of KT30, Defumm-8 and Luobeiqi at no Se treatment; 4,5 and 6 indicated varieties of KT30, Defumm-8 and Luobeiqi at $5 \mathrm{mg} \cdot \mathrm{kg}^{-1} \mathrm{Se}$ treatment; 7,8 and 9 indicated varieties of KT30, Defumm-8 and Luobeiqi at $5 \mathrm{mg} \cdot \mathrm{kg}^{-1} \mathrm{Se}$ treatment, respectively

enriched in seed, while the transformation and accumulation of Se were inhibited at Se deficiency in the soil. In this experiment, similar results were obtained. This may be because exogenous Se changed the activity of the Se transporter protein, and more Se was transported to shoots when the Se level was higher.

Many studies have proven that APS, APR, CysD, $M M T, S A T$ and $S M T$ were also the main genes for plant metabolism and Se accumulation (Berken et al., 2002; Tagmount et al., 2002; Van Hoewyk et al., 2008; Valdez Barillas et al., 2011). In this experiment, APS expression levels increased in leaves of three tomato varieties maybe due to Se induced the expression of APS, which was conducive to metabolism and accumulation of Se for tomato. After the application of Se, APR expression in levels of three varieties of tomato did not improve, and it markedly decreased in variety KT30 and variety Luobeiqi, probably, because the increase in expression levels of APS inhibited the reduction of ASP. Expression levels of variety KT30 and variety Defumm-8 in leaves decreased, whereas they increased in variety Luobeiqi; similar results were observed for MMT and SAT. In this experiment, the Se content in the fruit of variety Luobeiqi was the highest, which may be associated with higher expression levels of CysD, MMT, and SAT in variety Luobeiqi. Expression levels of SMT in leaves of variety KT30 and and variety
Luobeiqi were inhibited after Se treatment but increased in variety Defumm-8. SMT has been the major gene for plant metabolism and Se accumulation (Neuhierl and Bock, 2002; Nikiforova et al., 2003; Ellis et al., 2004). However, in this experiment, expression levels of SMT only increased in variety Defumm-8 after Se treatment; expression levels in variety KT30 and variety Luobeiqi decreased instead of increasing, indicating that further studies are required.

\section{Conclusion}

The Se content of tomato fruits, roots, stems and leaves markedly increased with the increase of Se concentration in soil. The Se content in three varieties of tomato was in the order of Luobeiqi $>$ KT30 $>$ Defumm-8. Different expression levels of APR, APS, CysD, MMT, SAT and SMT genes were found in different tomato varieties and different concentration. The higher expression levels of CysD, MMT, and SAT were found in Luobeiqi variety.

\section{Acknowledgments}

This work was supported by Fund of China Agriculture Research System (Nycytx-35-gw16), the National Science and Technology Pillar Program of China (No. 2007BAD87B10), the National Natural Science Foundation 
of China (No.31372141; 31672238), and the Ministry of Science and Technology of China (grant No. 2016YFD0100506); all are acknowledge. The first author gratefully thanks Dr. Hong Li at Lancaster Environment Centre, Lancaster University for reviewing the paper.

\section{References}

Arvy, M.P., 1993. Selenate and selenite uptake and translocation in bean plants. J. Exp. Bot., 44: 1083-1087

Avsian-Kretchmer, O. and S. Lev-Yadun, 2004. The salt-stress signal transduction pathway that activates the gpx 1 promoter is mediated by intracellular $\mathrm{H}_{2} \mathrm{O}_{2}$, different from the pathway induced by Extracellular $\mathrm{H}_{2} \mathrm{O}_{2}$. Plant Physiol., 135: 1685-1696.

Barry, C.S. and P. Pandey, 2009. A survey of cultivated heirloom tomato varieties identifies four new mutant alleles at the green-flesh locus. Mol. Breed., 24: 269-276

Berken, A., M.M. Mulholl and and D.L. LeDuc, 2002. Genetic engineering of plants to enhance selenium phytoremediation. Crit. Rev. Plant Sci., 21: 567-582

Chen, Y.M., J. Chen and W.D. Li, 2008. Influence of two kinds of seleniumenriched plants on hyperlipemia and lipid peroxidation in experimental hyperlipemic rats. Acta Nutr. Sin., 30: 262-265

Du, Y.X., Y.N. Li and D.Q. Chen, 2007. Progress in selenium metabolism and accumulation and key enzymes in plants. J. Tropi Subtrop. Bot., 15: $269-276$

Dunnill, P.M. and L. Fowden, 1967. The amino acids of the genus. Astragalus. Phytochemistry, 6: 1659-1663

Ellis, D.R., T.G. Sors and D.G. Brunk, 2004. Production of Semethylselenocysteine in transgenic plants expressing selenocysteine methyltransferase. BMC Plant Biol., 4: 1-11

Eustice, D.C., I. Foster and F.J. Kull, 1980. In vitro incoration of selenomethionine into protein by Vigna radiate polysomes. Plant Physiol., 66: 182-186

Finley, J.W. and C.D. Davis, 2001. Selenium (Se) from high-selenium broccoli is utilized differently than selenite, selenate and selenomethionine, but is more effective in inhibiting colon carcinogenesis. Biofactors, 14: 191-196

Freeman, J.L., L.H Zhang, M.A. Marcus, S. Fakra and E.A.H. Pilon-Smits, 2006. Spatial imaging, speciation and quantification of selenium in the hyperaccumulator plants Astragalus bisulcatus and Stanleya pinnata. Plant Physiol., 142: 124-134

Freeman, J.L., M. Tamaoki and C. Stushnoff, 2010. Molecular mechanisms of selenium tolerance and hyperaccumulation in stanleya pinnata. Plant Physiol., 153: 1630-1652

Fu, D.D., M.L. Duan and D.L. Liang, 2011. Effects of selenite and selenate on growth and nutrient absorption of pakchoi. Plant Nutr. Fert. Sci., 17: $358-365$

Kabelka, E., B. Franchino and D.M. Francis, 2002. Two loci from Lycopersicon hirsutum LA407 confer resistance to strains of Clavibacter michiganensis subsp. Michiganensis Phytopathol., 92: 504-510

Kyodan, Y., S. Tetsuya and Y. Munehim, 1988. Identification of selenomethionine in soybean protein. J. Agric Food Chem., 36: 463467

Levesque, H., F. Vedel and C. Mathieu, 1990. Identification of a short rDNA spacer sequence highly specific of a tomato line containing Tm-1 gene introgressed from Lycopersicon hirsutum. Theoretical Appl. Genet., 80: 602-608

Li, Z., N. Man, S. Wang, D. Liang and J. Liu, 2015. Selenite adsorption and desorption in main Chinese soils with their characteristics and physicochemical properties. J. Soils Sediments 15: 1150-1158

McCleod, S. 1975. Notes on Soil Techniques. Melbourne: CSIRO Division of Soils, 1975: 73-79

Miao, Y.C., L. Bai, C. Miao, J. Chen and C.P. Song, 2005. Progress in plant glutathione peroxidase. Chinese Bull. Bot., 22: 350-356
Mihara, H., T. Kurihara, T. Yoshimura, K. Soda and N. Esaki, 1997. Cysteine sulfinate desulfinase, a NIFS-like protein of Escherichia coli with selenocysteine lyase and cysteine desulfurase activities. Gene cloning, purification, and characterization of a novel pyridoxal enzyme. J. Biol. Chem., 272: 22417-22424.

Munierlamy, C., S. Deneuxmustin, C. Mustin, D. Merlet, J. Berthelin and C. Leyval, 2007. Selenium bioavailability and uptake as affected by four different plants in a loamy clay soil with particular attention to mycorrhizae inoculated ryegrass. J. Environ. Radioactivity, 97: 148158

Neuhierl, B. and A. Bock, 2002. Selenocysteine methyltransferase. Meth Enzymol., 347: 203-207

Nikiforova, V., J. Freitag and S. Kempa, 2003. Transcriptome analysis of sulfur depletion in Arabidopsis thaliana: interlacing of biosynthetic pathways provides response specificity. Plant $J$., 33: 633-650

Rayment, G. E. and F. R. Higginson, 1992. Australian Laboratory Handbook of Soil and Water Chemical Methods.: Inkata Press, Melbourne, Australia

Shi, H.P., Y.J. Zhang and Z.S. Liu, 1993. Absorption, distribution and transformation of selenium in the tomato plants. Acta Bot. Sin., 35: $541-546$

Sors, T.G., D.R. Ellis and G.N. Na, 2005. Analysis of sulfur and selenium assimilation in Astragalus plants with varying capacities to accumulate selenium. The Plant J., 42: 785-797

Tagmount, A., A. Berken and N. Terry, 2002. An essential role of Sadenosyl-L-methionine: 1methionine S-methyltransferase in selenium volatilization by plants. Methylation of selenomethionine to selenium-methyl-L-selenium- methionine, the precursor of volatile selenium. Plant Physiol., 130: 847-856

Terry, N., A. M. Zayed, M. P. de Souza and A. S. Tarun, 2000. Selenium in higherplants. Annu. Rev. Plant Physiol. Plant Mol. Biol., 51: 401-432.

Tian, Y. B., F. Chen, M. B. Xiong and G. Y. Song, 2005. Uptake, distribution and accumulation of selenium by ryegrass. Plant Nutr. Fert. Sci., 11: 122-127.

Valdez Barillas, J.R., C.F. Quinn and E.A. Pilon-Smits, 2011. Selenium accumulation in plants-phytotechnological applications and ecological implications. Int. J. Phytoremed., 13: 166-178

Van Hoewyk, D., M. Pilon and E.A.H. Pilon-Smits, 2008. The functions of NifS-like proteins in plant sulfur and selenium metabolism. Plant Sci., 174: 117-123

Wen, H.X., 2006. The influence of factors on selenium enrichment of mycelium of pleurotus ostreatus. Food Sci., 27: 52-54

Xiao, L.J., J.N. Lu, X.X. Liu and W.C. Yang, 2015. Genetics of fruit color and sequence variation of gf locus in brown tomato lines. Acta Hortic. Sin., 42: 38-46

Xie, W.W., S.J. Xiong and W.H. Xu, 2014. Effect of exogenous lanthanum on accumulation of cadmium and its chemical form in tomatoes. Wuhan University J. Natural Sci., 19: 221-228

Xu, W.H., A.G. Kachenko and B. Singh, 2010. Effect of soil properties on arsenic hyperaccumulation in pteris vittata and pityrogramma calomelanos var. austroamericana. Int. J. Phytoremed., 12: 174-187

Zayed, A., C.M. Lytle and N. Trry, 1998. Accumulation and volatilization of different chemical species of selenium by plants. Planta, 206: 284-292

Zhang, L.H., W.M. Shi and X.C. Wang, 2006. Genotypic differences in selenium accumulation in rice seedlings and correlation with selenium content in brown rice. J Plant Nutrition, 29: 1601-1618

Zhang, M., S.H. Tang and X. Huang, 2014. Selenium uptake, dynamic changes in selenium content and its influence on photosynthesis and chlorophyll fluorescence in rice (Oryza sativa L.). Environ. Exp. Bot., 107: 39-45

Zhou, X.B., C.M. Zhang, Y.K. Wang and W.H. Xu, 2016. Differences in selenium accumulation in grains of two rice cultivars. Bangl. J. Bot., 45: $811-818$

Zhou, X.B., W.M. Shi and L.Z. Yang, 2007. Genotypical differences and characteristics of Se uptake and accumulation in rice. Soil, 39: 731736

(Received 22 December 2016; Accepted 27 February 2017) 